\title{
Kt/V: A Magical Formula for Dialysis Adequacy: A Critical Review
}

\author{
Vajihe Biniaz, ${ }^{1}$ Hossein Karimi Moonaghi, ${ }^{1,}$ Razieh Froutan, ${ }^{1}$ and Abbass Ebadi ${ }^{2}$ \\ ${ }^{1}$ Department of Medical Surgical Nursing, School of Nursing and Midwifery, Mashhad University of Medical Sciences, Mashhad, IR Iran \\ ${ }^{2}$ Department of Medical Surgical Nursing, Baqiyatallah University of Medical Sciences, Tehran, IR Iran \\ "Corresponding author: Hossein Karimi Moonaghi; Department of Medical Surgical Nursing, School of Nursing and Midwifery, Mashhad University of Medical Sciences, \\ Mashhad, IR Iran. Tel: +98-9153155214, Fax: +98-5138597313, E-mail: karimih@mums.ac.ir
}

Received 2017 July 02; Revised 2017 August 08; Accepted 2017 October 03.

\begin{abstract}
Long-term prognosis of chronic hemodialysis patients is affected by dialysis adequacy; thus, evaluation of dialysis adequacy plays a key role in assessment of healthcare system in all countries. Currently, urea reduction ratio (URR) and Kt/V are applied to evaluate dialysis adequacy; however, due to the inconsistency between their results and patient outcome, their application has been questioned. Herein, we aimed at broadly reviewing the shortcomings of Kt/V index for appraisal of dialysis adequacy. For this purpose, we searched MEDLINE, EMBASE, Science direct, Cochrane Library, Scopus, and Google Scholar for relevant literature without any time or language limitations from May 2016 to February 2017. The applied keywords were "dialysis adequacy" OR “dialysis sufficiency" OR "dialysis competence" OR "dialysis efficiency". We summarized all the studies questioning the success of Kt/V index in appraisal of dialysis adequacy to investigate whether $\mathrm{Kt} / \mathrm{V}$ is still an appropriate index for evaluation of adequacy of different types of dialysis. The results of this study revealed that $\mathrm{Kt} / \mathrm{V}$ is not the best criterion and one cannot be assured of dialysis adequacy solely based on this criterion.
\end{abstract}

Keywords: Dialysis Adequacy, Kt/V, Dialysis Sufficiency, Dialysis Competence, Dialysis Efficiency

\section{Context}

Chronic kidney disease (CKD) is a progressive and irreversible malfunction with various systemic adverse effects (1). End stage renal disease (ESRD) is a condition in which the patient requires dialysis or renal transplant to survive. Annually, thousands of people die of ESRD (2). Change in parameters associated with lifestyle, such as hypertension and diabetes, can explain the rising incidence rate of this disease (3). The prevalence of this disease is on a growing trend in the developed and developing countries (4). According to the national health organization of America reports, the prevalence rate of this debilitating disease has increased by 600\% during 1980 and 2009 (5).

In Iran, prevalence and incidence of ESRD is also on the rise (6), so prevalence and incidence of ESRD, with an increase of 460 times, have risen from 137 per 1,000,000 cases in 1997 to 238 cases in 2000 and to 436 cases in $2007(7,8)$. Based on a report by the management center for transplantation and special diseases, approximately 33,000 patients received alternative therapies for kidney during $2007(8,9)$.

Hemodialysis replaces some of the renal functions in ESRD patients to remove waste products and extra fluids from the blood when the kidneys cannot function adequately $(10,11)$. Thus, with higher dialysis adequacy, the patient would have a better health status and would suffer less from adverse effects of renal failure (12). Long-term prognosis of hemodialysis patients is affected by dialysis adequacy (13). Dialysis adequacy is considered a predictor of patient mortality and primary outcomes (14). The patients undergoing dialysis with high adequacy live as long as those receiving kidney transplant $(15,16)$.

The Kt/V index, as a criterion for investigation of dialysis adequacy, was developed based on urea kinetics in early 1980s (17) and has been used as the only evaluation method (18).

Results of several studies during the last 20 years, reported lack of significant improvement in dialysis outcomes, and the rates of mortality and hospital admissions in hemodialysis patients (19). Numerous questions are asked in this regard, for instance, given the state-of-theart alternative strategies, is $\mathrm{Kt} / \mathrm{V}$ still an appropriate index for evaluation of adequacy of different types of modern dialysis? Do we have a thorough perception of dialysis adequacy? What are the possible problems or mistakes that can deviate our understanding of Kt/V? Accordingly, the status of dialysis patients in dialysis adequacy is a key factor in evaluation of healthcare systems and can help healthcare authorities to develop effective plans, promote quality of life, and lower healthcare costs, and the rates of morbidity and mortality in dialysis patients (20). This study broadly reviews the shortcomings of $\mathrm{Kt} / \mathrm{V}$ index to evaluate dialysis adequacy and summarize the drawbacks attributed to $\mathrm{Kt} / \mathrm{V}$ formula that impede accurate evaluation of dialysis adequacy to investigate whether Kt/V is still

Copyright (c) 2017, Jundishapur Journal of Chronic Disease Care. This is an open-access article distributed under the terms of the Creative Commons 
an appropriate index for evaluation of adequacy of different types of dialysis.

\subsection{Review Strategy}

In this study, we searched MEDLINE, EMBASE, Science direct, Cochrane Library, Scopus, and Google Scholar for relevant literature, without any time or language limitations from May 2016 to February 2017. The applied keywords were "dialysis adequacy" OR "dialysis sufficiency" OR "dialysis competence" OR "dialysis efficiency". All the studies that questioned the success of $\mathrm{Kt} / \mathrm{V}$ index in appraising dialysis adequacy were included to investigate whether Kt/V is still an appropriate index in evaluating adequacy of different types of dialysis. All the retrieved papers were screened for evidence on success of $\mathrm{Kt} / \mathrm{V}$ index in appraising dialysis adequacy.

\subsection{Ethical Approval}

Prior ethical approval was obtained from the institutional ethical committee at Mashhad University of Medical Sciences, Mashhad, Iran.

\section{Results}

\subsection{The Negative Points of Kt/V as a Marker ofDialysis Adequacy}

- In $\mathrm{Kt} / \mathrm{V}$, urea is considered the most important waste product distributed in a homogenous volume in the body (21). Nonetheless, since the 1960s, it has been known that several uremic toxins have greater molecular weight than urea and that urea distribution volume is not homogeneous, such that the level of blood urea significantly increases in post-dialytic urea rebound. Besides, individuals are essentially different in post-dialytic urea rebound, and neglecting these differences causes substantial errors (22).

- There is a broad spectrum of factors affecting urea accumulation and removal, which can highly influence the accuracy of Kt/V. Although the actual adequacy of dialysis might remain unchanged, several factors can increase $\mathrm{Kt} / \mathrm{V}$ after a dialysis session through changing the blood urea level at the end of dialysis including increased frequency or duration of dialysis, use of filters with high ultrafiltration index, high volume of blood entering the dialyzer, and enhancing the level of fluids flowing through the dialysis using such mechanisms as increasing ultrafiltration and urea diffusion through semipermeable membranes $(23,24)$. These factors, which can increase Kt/V, cannot be used in all dialysis sessions. Given the limited number of dialysis machines and low tolerance of patients, dialysis can rarely be performed more than 3 times a week or 4 hours a day (25).
The use of filters with high ultrafiltration index can promote adequacy of dialysis; however, it is not possible in all dialysis sessions and for all patients, as it cannot be tolerated by patients and it is not cost-effective. Promoting the level of blood entering the dialyzer is not feasible due to the type of vascular access and other factors, such as hypotension, muscular cramp, and in turn, patients' intolerance (26). On the other hand, raising the level of fluids flowing through the dialyzer increases the use of water in dialysis, and considering the effect of this issue on the removal of a sufficient amount of the built-up fluids, it cannot be applied in every dialysis session (17). Consequently, taking the $\mathrm{Kt} / \mathrm{V}$ promoting measures, such as increasing the fluid flow of dialyzer (27) and duration and frequency of hemodialysis more than once or twice a month, is not feasible.

- Former studies demonstrated that there are other uremic toxins than urea that are influential in uremic syndrome and have various behaviours in dialysis sessions depending on their size, weight, charge, distribution volume, and bonding with proteins. Thus, urea production and removal alone cannot exhibit all the spectrum of uremic toxicities (28). Furthermore, urea kinetics in dialysis is not similar to kinetics of numerous small solutes built up in uraemia (29), whereas Kt/V only employs the level of urea clearance for evaluation of dialysis adequacy (30).

The studies performed on chronic renal failure could not find a relationship between urea and the severity of uraemia symptoms. Thus, disappearance of uraemia symptoms, such as anorexia, nausea, vomiting, weakness, and fatigue, cannot indicate the sufficiency of dialysis, as with improvement of anaemia with erythropoietin and dialysis, although insufficient, numerous uraemia symptoms can be relieved (31).

- The recent studies suggest that body surface area should be taken into account in all mathematical models of adequacy, which indicates that few female and paediatric patients require increasing the dialysis dose to improve their outcomes; however, this factor has not been considered in the Kt/V formula (32).

- The results of previous studies demonstrated that mortality of ESRD patients, as an associated factor with dialysis dose and duration, is linked with gender and ethnicity. Some other studies, considering the effect of body fat and muscle percentage on dialysis adequacy, proposed that the admissible Kt/V should be different for males and females.

These studies determined the accepted Kt/V for men and women to be 1.25 and 1.65, respectively. Despite the fact that the effect of gender, ethnicity, and BMI on the accuracy of dialysis adequacy has been confirmed, the Kt/V formula has become confusing as gender and variation in each size correction factor can influence its accuracy (30). 
- Since the cooperation of patients through self-care behaviours can have positive effects on the physical and psychological side effects of dialysis, the patients should be updated about the details of their dialysis, which necessitates providing the information in a simple way without the use of medical terms. However, dialysis inadequacy is not evident to patients due to the convolutedness of the $\mathrm{Kt} / \mathrm{V}$ formula, even for the literate patients (33).

- The Kt/V formula was designed based on the methods and technologies of the time; consequently, the advances in dialysis technologies and methods, which might affect dialysis outcomes and adequacy, are not considered in this formula.

- The experimental studies performed in the recent years could not exhibit the consistency between $\mathrm{Kt} / \mathrm{V}$ and most of the dialysis outcome determinants. Based on their reports, higher Kt/V than the determined standard was not associated with improved outcomes in dialysis patients.

- Given that urea can be easily distributed in all the body fluids, urea distribution volume in the Kt/V formula was considered equal to the volume of body fluids, although it can affect the accuracy of the calculations in different people with diverse body compositions.

- The urea kinetic modelling has neglected the technical aspects of dialysis including ultrafiltration variations and the effect of filters with large pores and convection on the complete removal of small-solutes.

- Kt/V is not able to identify and calculate the effect of residual renal function on removal of small-solutes (24).

- Kt/V cannot reflect the kinetics of small-solutes that do not have added value, but can influence the removal of many other small-solutes.

- Kt/V does not effectively show the effect of dialysis on the electrolyte balance and volume (24).

- Since low urea reveals bad nutritional status and protein-energy malnutrition (34), rather than sufficient urea removal through dialysis, monitoring serial blood urea is not enough to evaluate dialysis adequacy (5).

- Stability of Kt/V level (1.2) has caused the adequacy and inadequacy borders to be close to each other.

- Kt/V index is dependent on blood tests that are prone to false-high results (30).

A summary of Kt/V criticisms is listed in Table 1.

\section{Discussion}

The results of this study revealed that $\mathrm{Kt} / \mathrm{V}$ is not the best criterion, and one cannot be assured of dialysis adequacy solely based on this criterion.

Considering that adequacy of dialysis is a concept associated with healthcare system, special attention has been paid globally to its significance for hemodialysis patients.
Review of the related literature illustrated that we do not have in-depth information on dialysis adequacy yet. Dialysis adequacy is concept rather than a number (35); thus, the main drawback of $\mathrm{Kt} / \mathrm{V}$ is the use of limited data for measuring a concept that can be affected by multiple factors (36). This type of concept cannot be gauged based on serial evaluation of the blood urea or investigation of the amount of removal of urea and the built up fluids in the blood (37). Perhaps, this is why higher dialysis frequency, using filters with high ultrafiltration index after reduction of $\mathrm{Kt} / \mathrm{V}$, has not been able to improve the clinical outcomes of hemodialysis patients (24).

An efficient dialysis, which can influence mortality and short- or long-term morbidity of dialysis patients, comprises of a wide range of characteristics (38). In other words, the dialysis adequacy algorithm includes subjective and objective aspects, and an efficient dialysis leads to a subjective feeling of well-being (29).

The multidimensional concept of hemodialysis adequacy (39) consists of objective and subjective dimensions (40). The objective aspect is associated with indices that are able to assess the physiological dimensions of dialysis adequacy using diverse tools. Kt/V, being an objective index, can gauge dialysis adequacy from this aspect. The subjective aspect cannot depend on blood and other biological fluids' clearance from a waste product and calculation of a laboratory parameter similar to a static quantity. Nevertheless, dialysis adequacy should be based on investigation of characteristics of each patient and focus on indices such as the time of dialysis, or the type of dialysis membranes, regardless of the characteristics of individuals, which leads to neglecting the subjective aspects of dialysis adequacy (41).

In fact, the subjective dimension of dialysis adequacy is based on the consistency between the admissible outcomes for the patient and the manageable costs and efforts (42). Patients' perception and experience of an efficient dialysis, subjective perception of the physical and spiritual-psychological signs of adequate dialysis, and patients' expectations and feelings about their health status during the dialysis procedure are all associated with subjective aspect of dialysis adequacy (43). On the other hand, the role of patients' problems and disorders, the admissible outcomes for the patients, the bearable costs and efforts, and the financial problems they face cannot be taken for granted (34). Thus, a comprehensive evaluation of dialysis adequacy requires a method that can take both subjective and objective aspects into account.

\subsection{Conclusions}

Although indices, such as Kt/V and URR, are currently the only methods for investigation of dialysis adequacy 
around the globe and their application is beneficial for preventing low dialysis adequacy, these objective markers are not the best criteria, and one cannot be assured of dialysis adequacy solely based on these criteria.

\subsection{Implication}

The magical formula for determining dialysis adequacy is still open to question, and further studies should be conducted to investigate all aspects of dialysis adequacy and find the best tool for evaluating all aspect of dialysis adequacy.

\section{Acknowledgments}

The present article was part of a PhD thesis in nursing, which was approved by Mashhad University of Medical Sciences.

\section{References}

1. Meyers AM. Significance, definition, classification and risk factors of chronic kidney disease in South Africa. S Afr Med J. 2015;105(3):233-6. [PubMed: 26294833].

2. Hamer RA, El Nahas AM. The burden of chronic kidney disease. BMJ. 2006;332(7541):563-4. doi: 10.1136/bmj.332.7541.563. [PubMed: 16528062].

3. Hallan S, de Mutsert R, Carlsen S, Dekker FW, Aasarod K, Holmen J. Obesity, smoking, and physical inactivity as risk factors for CKD: are men more vulnerable? Am J Kidney Dis. 2006;47(3):396-405. doi: 10.1053/j.ajkd.2005.11.027. [PubMed: 16490617].

4. Biniaz V, Sadeghi Shermeh M, Ebadi A, Tayebi A, Einollahi B. Effect of Vitamin C Supplementation on C-reactive Protein Levels in Patients Undergoing Hemodialysis: A Randomized, Double Blind, PlaceboControlled Study. Nephrourol Mon. 2014;6(1):e13351. doi: 10.5812/numonthly.13351. [PubMed: 24719806].

5. National Kidney and Urologic Diseases Information Clearinghouse (NKUDIC) . Kidney Disease Statistics for the United States. NIH Publication; 2012.

6. Pourebrahimi M, Rahimi A, Tayebi A, Ebrahimi H. The effect of consuming oral Vitamin C on exhaustion of hemodialysis patient caregivers. J Crit Care Nurs. 2013;6(2):95-100.

7. Mousavi SS, Soleimani A, Mousavi MB. Epidemiology of end-stage renal disease in Iran: a review article. Saudi J Kidney Dis Transpl. 2014;25(3):697-702. [PubMed: 24821181].

8. Kharame ZT, Zamanian H, Foroozanfar S, Afsahi S. Religious wellbeing as a predictor for quality of life in Iranian hemodialysis patients. Glob J Health Sci. 2014;6(4):261.

9. Tayyebi A, Savari S, Nehrir B, Rahimi A, Eynollahi B. The effect of Vitamin B12supplemention on fatigue in hemodialysis patients.J Crit Care Nurs. 2013;6(1):39-48.

10. Pandya P, Farrington K. Haemodialysis. Medicine. 2003;31(6):66-9. doi: 10.1383/medc.31.6.66.28304.

11. Eshghizadeh M, Basirimoghadam K, Baloochi BT, Safarpoor GZ, Mokhtari S. Dialysis adequacy in diabetic and non-diabetic patients admitted to a hospital in gonabad, iran in 2012. Med Surg Nurs $J$. 2014;3(2):77-83.

12. Abasi M, Lesan Pezeshki M, Asadi N. Study of the Relationship between Vascular Access Types and Recirculation in Chronic Hemodialysis. SJIMU. 2015;23(5):81-90.
13. Zeraati AA, Naghibi M, Jabbari Noghabi H. Factors affecting the adequacy of dialysis in hemodialysis patients. J Med Sci. 2008;51(99):4552.

14. Abdelwahab H, Shigidi M, El-Tohami A, Ibrahim L. Adherence of healthcare professionals to evidence-based clinical practice guidelines in the management of hemodialysis patients, Khartoum State, Sudan. Arab J Nephrol Transplant. 2013;6(2):99-104. [PubMed: 23656403].

15. Saad MM, El Douaihy Y, Boumitri C, Rondla C, Moussaly E, Daoud M, et al. Predictors of quality of life in patients with end-stage renal disease on hemodialysis. Int J Nephrol Renovasc Dis. 2015;8:119-23. doi: 10.2147/IJNRD.S84929. [PubMed: 26366104].

16. Englishdictionary . Dictionary 2015. Available from: http: //englishdictionary.education/en/adequacy.

17. Bennett PN. Exercise adequacy in dialysis. Renal Soc Aust J. 2012;8(2):52-3.

18. Daugirdas JT. Dialysis dosing for chronic hemodialysis: beyond Kt/V. Semin Dial. 2014;27(2):98-107. [PubMed: 24738145].

19. Cheung AK, Levin NW, Greene T, Agodoa L, Bailey J, Beck G, et al. Effects of high-flux hemodialysis on clinical outcomes: results of the HEMO study. J Am Soc Nephrol. 2003;14(12):3251-63. [PubMed: 14638924].

20. Sehgal AR. Improving hemodialysis patient outcomes: a step-by-step approach. Semin Dial. 2002;15(1):35-7. [PubMed: 11874590].

21. Kooman JP, van der Sande FM, Leunissen KM. Kt/V: finding the tree within the woods. Nephrol Dial Transplant. 2001;16(9):1749-52. [PubMed: 11522851]

22. Tomson R, Fridolin I, Luman M, Holmar J. Mp448the Effect of $\mathrm{Kt} / \mathrm{V}$ on Post Dialysis Urea Rebound in Hemodialysis and Hemodiafiltration. Nephrol Dialysis Transplant. 2016;31(suppl_1):i490. doi: 10.1093/ndt/gfw194.03.

23. Borzou SR, Gholyaf M, Zandiha M, Amini R, Goodarzi MT, Torkaman B. The effect of increasing blood flow rate on dialysis adequacy in hemodialysis patients. Saudi J Kidney Dis Transpl. 2009;20(4):639-42. [PubMed: 19587507].

24. Barzegar H, Moosazadeh M, Jafari H, Esmaeili R. Evaluation of dialysis adequacy in hemodialysis patients: A systematic review. Urol J. 2016;13(4):2744-9. [PubMed: 27576879].

25. Cigarran S, Coronel F, Torrente J, Sevilla M, Baylón JCD. Risk of Inadequate Dialysis Dose in Hemodialysis Patients with High Watson Volume. A Warning. Hemodialysis Int. 2004;8(1):84. doi: 10.1111/j.14927535.2004.00850.x.

26. Hauk M, Kuhlmann MK, Riegel W, Kohler H. In vivo effects of dialysate flow rate on Kt/V in maintenance hemodialysis patients. Am J Kidney Dis. 2000;35(1):105-11. doi: 10.1016/S0272-6386(00)70308-8. [PubMed: 10620551].

27. Nafar M, Samavat S, Khoshdel A, Abedi BA. Dialysis Adequacy, Dialyzer Clearance, and Strategies to Achieve Target: A Nationwide Multicenter Study. Nephro Urol Mon. 2017;9(1).

28. Mehta AN, Fenves AZ. Hemodialysis Adequacy: A Review.Dialysis Transplant. 2010;39(1):20-2. doi: 10.1002/dat.20392.

29. Vanholder R, Glorieux G, Eloot S. Once upon a time in dialysis: the last days of Kt/V? Kidney Int. 2015;88(3):460-5. doi: 10.1038/ki.2015.155. [PubMed: 26061543]

30. U.S Department of Health and Human Services . Hemodialysis dose and adequacy.Nih publication, no.03-4556.;2003.

31. Kuo CC, Lee CT, Chuang CH, Su Y, Chen JB. Recombinant human erythropoietin independence in chronic hemodialysis patients: clinical features, iron homeostasis and erythropoiesis. Clin Nephrol. 2005;63(2):92-7. [PubMed: 15730050].

32. Himmelfarb J, Ikizler TA. Hemodialysis. $N$ Engl $J$ Med. 2010;363(19):1833-45. doi: 10.1056/NEJMra0902710. [PubMed: 21047227].

33. Bhimani JP, Ouseph R, Ward RA. Effect of increasing dialysate flow rate on diffusive mass transfer of urea, phosphate and beta2microglobulin during clinical haemodialysis. Nephrol Dial Transplant. 2010;25(12):3990-5. doi: 10.1093/ndt/gfq326. [PubMed: 20543211]. 
34. Afaghi E, Tayebi A, Ebadi A, Sobhani V, Einollahi B, Tayebi M. The effect of BCAA and ISO-WHEY oral nutritional supplements on dialysis adequacy. Nephro Urol Mon. 2016;8(6).

35. Depner TA. Benefits of more frequent dialysis: lower TAC at the same Kt/V.Nephrol Dial Transplant. 1998;13 Suppl 6:20-4. [PubMed: 9719199]

36. Omrani VF, Fallahi S, Rostami A, Siyadatpanah A, Barzgarpour G Mehravar S, et al. Prevalence of intestinal parasite infections and associated clinical symptoms among patients with end-stage renal disease undergoing hemodialysis. Infection. 2015;43(5):537-44. doi: 10.1007/s15010-015-0778-6. [PubMed: 25869822].

37. Watnick S. Peritoneal Dialysis Adequacy 2011. Available from: ispd.org/.../Peritoneal-Dialysis-Adequacy-Watnick-April-2011Notes.pdf.

38. Canaud B. Adequacy target in hemodialysis. J Nephrol. 2004;17 Suppl 8:S77-86. [PubMed: 15599891].

39. Kerr P, Perkovic V, Petrie J, Agar J, Disney A, Caring for Australians with Renal I. The CARI guidelines. Dialysis adequacy (HD) guidelines. Nephrology (Carlton). 2005;10 Suppl 4:S61-80. doi: 10.1111/j.14401797.2005.00464_1.x. [PubMed:16221128].

40. Fouad T, Mokhtar Y. Principle factors affecting adequacy of dialysis. Assessment of adequacy of dialysis 2003. Available from: http://www.doctorslounge.com/nephrology/articles/dialysis_ adequacy/adeq1.htm.

41. Aggarwal HK, Jain D, Sahney A, Bansal T, Kathuria KL. Effect of dialyser reuse on the efficacy of haemodialysis in patients of chronic kidney disease in developing world. JIMSA. 2012;25(2):81-3.

42. Gayle F, Soyibo AK, Gilbert DT, Manzanares J, Barton EN. Quality of life in end stage renal disease: a multicentre comparative study. West Indian Med J. 2009;58(3):235-42. [PubMed: 20043531].

43. Al Onazi M, Al Jondeby M, Azeem M, Al Sayyari A. Factors affecting Saudi hemodialysis patients' perception of healthcare providers' empathy. Arab J Nephrol Transplant. 2011;4(2):71-6. [PubMed: 21999854]. 
Table 1. Kt/V Critisms

\begin{tabular}{|c|c|c|c|c|}
\hline Article Type & Publication Year & Negative Points & First Author & Reference Number \\
\hline \multirow{2}{*}{ Review } & \multirow{2}{*}{2001} & $\begin{array}{l}\text { 1-Urea is not the most important waste } \\
\text { product, but several uremic toxins have } \\
\text { greater molecular weight than urea. }\end{array}$ & \multirow{2}{*}{ Jeroen P } & \multirow{2}{*}{ (21) } \\
\hline & & $\begin{array}{l}\text { 2- Urea distribution volume is not } \\
\text { homogeneous. }\end{array}$ & & \\
\hline RCT & 2016 & $\begin{array}{l}\text {-Individuals are essentially different in } \\
\text { post-dialytic urea rebound because level } \\
\text { of blood urea significantly increases in } \\
\text { post-dialytic urea rebound. }\end{array}$ & Tomson R & (22) \\
\hline RCT & 2004 & $\begin{array}{l}\text { - Although the actual adequacy of dialysis } \\
\text { might remain unchanged, several factors } \\
\text { can only increase Kt/V after a dialysis } \\
\text { session. }\end{array}$ & Kim O & (23) \\
\hline \multirow{8}{*}{ Systhematic review } & \multirow{8}{*}{2016} & $\begin{array}{l}\text { 1- Many factors could increase Kt/V after a } \\
\text { dialysis session. }\end{array}$ & \multirow{8}{*}{ Barzegar $\mathrm{H}$} & \multirow{8}{*}{ (24) } \\
\hline & & $\begin{array}{l}\text { 2-Advances in dialysis technologies and } \\
\text { methods, which might affect dialysis } \\
\text { outcomes and adequacy, are not } \\
\text { considered in this formula. }\end{array}$ & & \\
\hline & & $\begin{array}{l}\text { 3-There is not any consistency between } \\
\mathrm{Kt} / \mathrm{V} \text { and most of the dialysis outcome } \\
\text { determinants. }\end{array}$ & & \\
\hline & & $\begin{array}{l}\text { 4- There is no differrance in calculations } \\
\text { of Kt/V formula between different people } \\
\text { with diverse body compositions. }\end{array}$ & & \\
\hline & & $\begin{array}{l}\text { 5-The urea kinetic modelling has } \\
\text { neglected the technical aspects of dialysis } \\
\text { including ultrafiltration variations and } \\
\text { the effect of filters with large pores and } \\
\text { convection on the complete removal of } \\
\text { small-solutes. }\end{array}$ & & \\
\hline & & $\begin{array}{l}\text { 6- Kt/ } / \mathrm{V} \text { is not able to identify and calculate } \\
\text { the effect of residual renal function on } \\
\text { removal of small-solutes. }\end{array}$ & & \\
\hline & & $\begin{array}{l}\text { 7-Kt/V cannot reflect the kinetics of } \\
\text { small-solutes that do not have added } \\
\text { value, but can influence the removal of } \\
\text { many other small-solutes. }\end{array}$ & & \\
\hline & & $\begin{array}{l}\text { 8- Kt } / V \text { does not effectively show the effect } \\
\text { of dialysis on the electrolyte balance and } \\
\text { volume. }\end{array}$ & & \\
\hline Cross-sectional study & 2004 & $\begin{array}{l}\text { - Factors, which can increase Kt/V, cannot } \\
\text { be used in all dialysis sessions. }\end{array}$ & Cigarran S & (25) \\
\hline RCT & 2000 & $\begin{array}{l}\text {-The use of filters with high } \\
\text { ultrafiltration index can promote } \\
\text { adequacy of dialysis; however, it is not } \\
\text { possible in all dialysis sessions and for all } \\
\text { patients, as it cannot be tolerated by } \\
\text { patients, and it is not cost-effective. }\end{array}$ & Hauk M & (26) \\
\hline Cross-sectional study & 2017 & $\begin{array}{l}\text { - Taking the Kt/V promoting measures is } \\
\text { not feasible more than once or twice a } \\
\text { month. }\end{array}$ & Nafar M & (27) \\
\hline Review & 2010 & $\begin{array}{l}\text { - Urea production and removal alone } \\
\text { cannot exhibit all the spectrum of uremic } \\
\text { toxicities. }\end{array}$ & Mehta A.N & (28) \\
\hline Review & 2015 & $\begin{array}{l}\text { - Urea kinetics in dialysis is not similar to } \\
\text { kinetics of numerous small solutes built } \\
\text { up in uraemia. }\end{array}$ & Vanholder R & (29) \\
\hline \multirow{4}{*}{ Governmental Announcement } & \multirow{4}{*}{2003} & $\begin{array}{l}\text { 1- Factors such as gender, ethnicity, and } \\
\text { BMI can impress the accuracy of dialysis } \\
\text { adequacy; this factor has not been } \\
\text { considered in the Kt/V formula. }\end{array}$ & \multirow{4}{*}{$\begin{array}{l}\text { U.S Department of Health and Human } \\
\text { Services. }\end{array}$} & \multirow{4}{*}{ (30) } \\
\hline & & $\begin{array}{l}\text { 2- Stability of Kt/V level }(1.2) \text { has caused } \\
\text { the adequacy and inadequacy borders to } \\
\text { be close to each other. }\end{array}$ & & \\
\hline & & $\begin{array}{l}\text { 3-Kt/V index is dependent on blood tests } \\
\text { that are prone to false-high results. }\end{array}$ & & \\
\hline & & $\begin{array}{l}\text { 4- Some studies, considering the effect of } \\
\text { body fat and muscle percentage on } \\
\text { dialysis adequacy, proposed that the } \\
\text { admissible Kt/V should be different for } \\
\text { males and females. }\end{array}$ & & \\
\hline RCT & 2005 & $\begin{array}{l}\text {-There is not any relationship between } \\
\text { urea and the severity of uraemia } \\
\text { symptoms. }\end{array}$ & Kuo C.C & (31) \\
\hline
\end{tabular}




\begin{tabular}{|c|c|c|c|c|}
\hline Review & 2010 & $\begin{array}{l}\text { - The recent studies suggest that body } \\
\text { surface area should be taken into account } \\
\text { in all mathematical models of adequacy, } \\
\text { however, this factor has not been } \\
\text { considered in the Kt/V formula. }\end{array}$ & Himmelfarb J & (32) \\
\hline RCT & 2010 & $\begin{array}{l}\text { - However, hemodialysis patients should } \\
\text { be updated about the details of their } \\
\text { dialysis in a simple way without the use of } \\
\text { medical terms. Kt/V formula calculation } \\
\text { is difficult for dialysis patients. }\end{array}$ & Bhimani P & (33) \\
\hline RCT & 2016 & $\begin{array}{l}\text { - Low urea reveals bad nutritional status } \\
\text { and protein-energy malnutrition rather } \\
\text { than sufficient urea removal through } \\
\text { dialysis. Monitoring serial blood urea is } \\
\text { not enough for evaluation of dialysis } \\
\text { adequacy. }\end{array}$ & Afaghi E & (34) \\
\hline
\end{tabular}

